\title{
MACROECONOMIC FLUCTUATIONS AND THE ALLOCATION OF TIME
}

Robert E. Hall

Working Paper 5933

\section{NATIONAL BUREAU OF ECONOMIC RESEARCH 1050 Massachusetts Avenue \\ Cambridge, MA 02138 \\ February 1997}

This paper is part of NBER's research program in Economic Fluctuations and Growth. Any opinions expressed are those of the author and not those of the National Bureau of Economic Research.

(C) 1997 by Robert E. Hall. All rights reserved. Short sections of text, not to exceed two paragraphs, may be quoted without explicit permission provided that full credit, including $\mathbb{C}$ notice, is given to the source. 
Macroeconomic Fluctuations and the

Allocation of Time

Robert E. Hall

NBER Working Paper No. 5933

February 1997

JEL No. E32

Economic Fluctuations and Growth

\section{ABSTRACT}

What are the fundamental driving forces of macroeconomic fluctuations? In particular, why do people spend more time working in booms and less in recessions? These are basic questions of macroeconomics. Recent thinking has emphasized technology shifts, preference shifts, and changes in government purchases as likely driving forces. It is useful to distinguish atemporal and intertemporal effects of the driving forces. Under standard assumptions, the technology shift has no effect through atemporal channels because income and substitution effects exactly offset. A straightforward decomposition of movements of employment attributes most of them to the atemporal effects of preference shifts.

Robert E. Hall

Hoover Institution

and Department of Economics

Stanford University

Stanford, CA 94305-6010

and NBER

hall@hoover.stanford.edu 


\section{Introduction}

Recessions are times when the public spends less time working and more time in other pursuits, including job seeking and activities at home. A leading question in macroeconomics is the identification of the underlying force that causes this cyclical shift in the allocation of time. Modern stochastic intertemporal general equilibrium models in the tradition of Kydland and Prescott (1982) hypothesize that random shifts in technology drive aggregate fluctuations. Others have proposed shifts in government purchases, random variations in preferences, and movements in household productivity as additional driving forces. Although previous research has not considered spontaneous shifts in investment and net exports as potential driving forces in general equilibrium models, such shifts should be added to the list to make it complete

My purpose in this paper is to consider the relative importance of these various driving forces. The research strategy is novel. The paper emphasizes the distinction between atemporal and intertemporal analysis. A key point is that standard and plausible assumptions about the time-separability of preferences and technology imply that all intertemporal mechanisms operate through a single variable, namely investment. Atemporal conditions place sharp restrictions on the joint behavior of the major macroeconomic variables conditional on the level of investment.

Prominent in the atemporal analysis is the household's choice between work in the market and time spent in non-market activities. The standard first-order condition for this choice and the standard assumption that workers are paid their marginal products leads to a system of equations that identifies the three driving forces of preference shifts, technology shifts, and changes in government purchases, but not the residual driving force. The residual is combined with all intertemporal effects caused by the first three driving forces. A central empirical finding is the low volatility of the combined variable. Intertemporal mechanisms are unlikely to play a major role in macro fluctuations. For the same reason, it is unlikely that the residual is a major driving force.

It is well accepted that technology shifts are unlikely to be an important driving force through atemporal mechanisms, because their income and substitution effects are 
likely to be offsetting ${ }^{1}$. Models that put technology shifts in the forefront of fluctuations theory emphasize intertemporal mechanisms. The findings here cast doubt on the relevance of those mechanisms. Under the hypothesis that the residual driving force is uncorrelated with the three observable driving forces, the strength of the intertemporal effects of technology shifts is revealed directly from the relation between investment and the observed shifts. The relation is not strong enough to give technology shifts much of a role in the explanation of employment fluctuations.

All theories agree that fluctuations in government purchases could be an important driving force. Reductions in government purchases have generally occurred during recessions. However, the magnitude of the fluctuations is too small to make this driving force quantitatively important under reasonable assumptions about structural parameters.

Much the most important driving force in the empirical decomposition of changes in total working hours is the preference shift. The larger part of the influence of the shift is through the direct atemporal mechanism. Like the technology shift, the intertemporal role of the preference shift is identified through its correlation with investment. That correlation is fairly small.

Taken at face value, the decomposition says that recessions occur because people decide to consume fewer produced goods and spend more time at home. My own interpretation of these findings does not take the decomposition at face value. Rather, 1 believe that the findings demonstrate strongly that the stress on technology shifts and intertemporal mechanisms that has pervaded fluctuations research over the past decade has been misplaced. The key to better understanding of recessions is a richer atemporal analysis of the various ways that people spend their time. The proper interpretation of the findings is that recessions are times when circumstances change in a way that causes people to spend time in activities, such as job search, that are neither market work nor the enjoyment of time at home.

\footnotetext{
${ }^{1}$ From the starting point of modern intertemporal stochastic macro models (Kydland and Prescott (1982)), this assumption has been close to universal. It is imposed by having consumption enter the kernel of the utility function as $\log c$. An important exception is Kennan (1988).
} 
The approach in this paper is in the framework of formal intertemporal, stochastic general equilibrium models as pioneered by Kydland and Prescott (1982). The driving forces under consideration are shifts in fundamentals-technology, preferences, and government purchases. The objectives are similar to work in the framework of supply and demand, notably Shapiro and Watson (1988) and Blanchard and Quah (1989). But supply and demand are not fundamental concepts in general equilibrium theory; interpretation of results about supply shifts and demand shifts is tricky. ${ }^{2}$ Nonetheless, the findings in this paper are completely consistent with those in the supply-and-demand frameworkparticularly Shapiro and Watson's finding of the importance of shifts in labor supply at business-cycle frequencies. The findings are also consistent with Cochrane's (1994) inferences about intertemporal stochastic general equilibrium models based on the comparison of theoretical and actual vector autoregressions.

\section{Implications of the Household's Atemporal Time Allocation Decision}

The representative household maximizes the expected value of an intertemporal utility function whose period utility is

$$
x \log c-\frac{n^{1+\phi}}{1+\phi}
$$

where $c$ is consumption and $n$ is hours of work. The parameters of preferences are $x$, a random weight applied to consumption of goods and $\phi$, the elasticity of the marginal value of time. ${ }^{3}$ The compensated elasticity of labor supply is $1 / \phi$. Consumption enters in $\log$ form in order to impose the constraint that the atemporal labor supply function of a household with no outside income is wage-inelastic. Absent this constraint, the historical

\footnotetext{
${ }^{2}$ See my discussion of Shapiro and Watson (1988).

${ }^{3}$ Although preference shifts have been prominent in recent contributions to stochastic general equilibrium macroeconomics, there is some diversity in the way they enter the kernel of the utility function. Baxter and King (1991) subtract the random shift from consumption, so the shift becomes an additive component of the household's Frisch demand function for current goods consumption. Kennan (1988) posits a random shift in the linear part of quadratic preferences. Parkin (1988) and Bencivenga (1992) use essentially the same specification as mine.
} 
upward trend of real wages would induce a positive or negative trend in hours of work, contrary to the evidence. The first-order necessary condition for choice between current goods consumption and labor supply is:

$$
\frac{c n^{\phi}}{x}=w
$$

Here $w$ is the real wage.

The firm's production function is

$$
y=\frac{z}{\alpha} n^{\alpha} k^{1-\alpha}
$$

Here $y$ is output, $z$ is an efficiency parameter that fluctuates randomly, $n$ is the firm's employment measured as hours of work, $k$ is the capital stock, and $\alpha$ is the elasticity of output with respect to labor input, a positive parameter.

The firm's marginal product of labor is

$$
z\left(\frac{k}{n}\right)^{1-\alpha}
$$

The condition for equilibrium in the labor market requires that the marginal rate of substitution equal the marginal product of labor:

$$
\frac{c n^{\phi}}{x}=z\left(\frac{k}{n}\right)^{1-\alpha}
$$

At this point I will redefine all of the variables as logs of their earlier counterparts. The condition for labor supply is

$$
-x+c+\phi n=z+(1-\alpha)(k-n)
$$


The technology is

$$
y=z+\infty n+(1-\alpha) k-\log \alpha
$$

The third equation of the system states the relation between consumption and production:

$$
c=y-v-g
$$

Here $v$ is fraction of GDP devoted to investment and $g$ is the fraction used by the government. I use the term investment to include both capital accumulation and accumulation of claims on foreigners. Note that, because the variables are in logs, this equation is not the GDP identity (If the identity is $Y=C+V+G$, the exact definitions are $v=-\log (1-V /(Y-G))$ and $g=-\log (1-G / Y))$.

Conditional on the value of investment, $v$, these conditions can be solved. To this end, let

$$
\lambda=\frac{1}{1+\phi}
$$

the elasticity of total hours of work with respect to government purchases, $g$, and

$$
\mu=\alpha \lambda
$$

the elasticity of output with respect to government purchases. Employment bears the following relation to the driving forces:

$$
n=\lambda(x+v+g+\log \alpha)
$$


This gives

Proposition. In an intertemporal economy with uncertainty, under the stated assumptions, the level of work effort is related to the preference shift, $x$, investment, $v$, and government purchases, $g$, according to the nonstochastic structural relation of equation 2.11.

The corresponding log-linear restrictions for output and consumption are:

$$
y=z+\mu(x+v+g)+(1-\alpha) k-(1-\mu) \log \alpha
$$

and

$$
c=z+\mu \alpha-(1-\mu)(\nu+g)+(1-\alpha) k-(1-\mu) \log \alpha
$$

The inverse relationship, showing how to calculate the driving forces from the observed variables, is:

Technology shift: $\quad z=y-\alpha n-(1-\alpha) k+\log \alpha$

MRS shift:

$$
x=c-y+(1+\phi) n-\log \alpha
$$

Investment:

$$
v=y-c-g
$$


Baxter and King (1991) make use of the direct observability of the preference shift expressed in equation 2.15. They mention Hall (1986) and Parkin (1988) as making the same point earlier.

\section{Full Effects of Driving Forces}

The equations of the previous section show the atemporal effects of the driving forces. These would be the full effects in an economy with no opportunities for intertemporal trade, that is, no capital accumulation and no foreign trade. When trade opportunities exist, investment will respond to preference shifts, technology shifts, changes in government purchases, and other influences. The analysis of this relationship is responsible for all of the complexity of numerical general equilibrium macro models. ${ }^{4} \mathrm{I}$ will take a purely empirical approach to the link between the observed driving forces and investment. Under the assumption that the driving forces follow stationary stochastic processes, a reasonable model of the relationship is

$$
v=\beta_{x}(L) x+\beta_{z}(L) z+\beta_{g}(L) g+u
$$

Here the $\beta$ s are polynomials in the lag operator, $L$, and $u$ is the part of investment associated with other influences, including the spontaneous element of purchases of capital goods and changes occurring in other countries. In the econometric application of this equation, I will assume that the $\beta$ s are third-order and that $u$ obeys a second-order autoregressive process.

To identify the parameters of this equation, I will make the strong assumption that the residual element of investment, $u$, is uncorrelated with the observed driving forces. That is, shifts in preferences, technology, and government spending do not induce changes in the spontaneous part of capital goods accumulation or in the rest of the world, nor do the residual driving forces change preferences, technology, or government

\footnotetext{
4 This point comes through clearly in Baxter and King (1991). They show that the relation between investment and driving forces is remarkably sensitive to the specification of fundamentals.
} 
purchases. The most obvious reason that this assumption might fail is that preferences, technology, and government purchases are correlated across countries. The results will interpret these correlated elements as part of the intertemporal effects of domestic driving forces, rather than assigning them properly to the residual category.

The result is a 6-way decomposition of movements in employment:

$$
n=\lambda x+\lambda \beta_{x}(L) x+\lambda \beta_{z}(L) z+\lambda g+\lambda \beta_{g}(L) g+\lambda u
$$

The components are:

\begin{tabular}{|c|c|}
\hline$\lambda x$ & atemporal effect of preference shift \\
\hline$\lambda \beta_{x}(L) x$ & $\begin{array}{l}\text { intertemporal effect of preference } \\
\text { shift }\end{array}$ \\
\hline$\lambda \beta_{z}(L) z$ & $\begin{array}{l}\text { intertemporal effect of technology } \\
\text { shift }\end{array}$ \\
\hline$\lambda g$ & $\begin{array}{l}\text { atemporal effect of government } \\
\text { purchases }\end{array}$ \\
\hline$\lambda \beta_{g}(L) g$ & $\begin{array}{l}\text { intertemporal effect of government } \\
\text { purchases }\end{array}$ \\
\hline$\lambda u$ & effect of residual driving forces \\
\hline
\end{tabular}

\section{Parameter Values}

For the elasticity of the marginal disutility of work, $\phi$, I use the value of 1.7 , corresponding to a compensated elasticity of labor supply of 0.6 , in line with empirical results on static labor supply (recall that this parameter has a role only in atemporal labor supply; intertemporal effects could be much larger). For the elasticity of output with respect to labor input, $\alpha$, I use the value 0.7 . The results are not at all sensitive to either of these parameters. The implied values of the derived parameters are: 


\begin{tabular}{cccc}
\hline$\phi$ & $\alpha$ & $\lambda$ & $\mu$ \\
\hline $\begin{array}{c}\text { Elasticity of } \\
\text { marginal } \\
\text { disutility of } \\
\text { work }\end{array}$ & $\begin{array}{c}\text { Elasticity of } \\
\text { firm's output } \\
\text { with respect to } \\
\text { labor input }\end{array}$ & $\begin{array}{c}\text { Elasticity of } \\
\text { total hours } \\
\text { with respect } \\
\text { to spending } \\
\text { shift }\end{array}$ & $\begin{array}{c}\text { Elasticity of } \\
\text { output with } \\
\text { respect to } \\
\text { spending shift }\end{array}$ \\
\hline 1.7 & 0.7 & .38 & .26 \\
\hline
\end{tabular}

\section{Frequency Decomposition}

A three-way decomposition by frequency seems to help in understanding the issues considered here. I define the decomposition operators $L, M$, and $H$, for low, medium, and high frequencies, in the following way: Let $P_{N} x_{t}$ be the projection of a time series $x_{t}$ on $1, t, \ldots, t^{N}$. Then, for integers $d$ and $D, d<D$, let

$$
\begin{gathered}
L=P_{d} \\
M=P_{D}-L \\
H=1-L-M
\end{gathered}
$$

Although most approaches to decomposing time series by frequency are based on trigonometric functions, polynomials seem to serve the current purposes better. In particular, if $d$ is one or higher, the low-frequency component includes a linear trend. I use $d=1$ and $D=6$. That is, the low-frequency component is just a (log) linear trend; the medium frequency component is a 5 th-order polynomial fitted to the detrended data, and the high-frequency component is the vector of residuals from the trend and polynomial. The three components are orthogonal.

The frequency decomposition is only used to display the data; it has no role in estimation. 


\section{Data}

All data are quarterly. Sources are:

$N \quad$ Hours of all persons, business sector, index, U.S. Bureau of Labor Statistics, divided by adult population, U.S. Bureau of the Census, P-25.

$Y \quad$ Gross domestic product in 1987 dollars, U.S. national income and product accounts plus imputed service value of consumer durables, divided by population

C Personal consumption expenditures for nondurables and services plus imputed service value of consumer durables in 1987 dollars, U.S. national income and product accounts, divided by population

$V \quad$ Investment plus purchases of consumer durables plus net exports, U.S. national income and product accounts, divided by population

G Government purchases in 1987 dollars, U.S. national income and product accounts, divided by population

I calculated the capital stock by cumulating the investment series, $V$, with 10 percent annual deterioration of capital. To obtain the service flow from consumer durables, I cumulated the durables component of investment, also at a 10 percent annual rate, and multiplied the resulting estimate of the durables stock by 15 percent to convert to a service flow. ${ }^{5}$

Figure 1 shows the high-frequency component of total hours of work. The component captures the standard business cycle-the shaded areas are cyclical contractions. Each coincides with a recession in the NBER chronology, but the peak and trough dates are determined purely by the hours series. The same shaded areas appear in

\footnotetext{
${ }^{5}$ All data were obtained from Citibase. A program showing the details of all calculations is available from the author.
} 
every high-frequency plot in the paper, to facilitate comparison of the movements of the other data series and the derived series for the driving forces. Also, the same vertical scale is used in all high-frequency plots.

Figure 1. Hours of Work at High

Frequencies

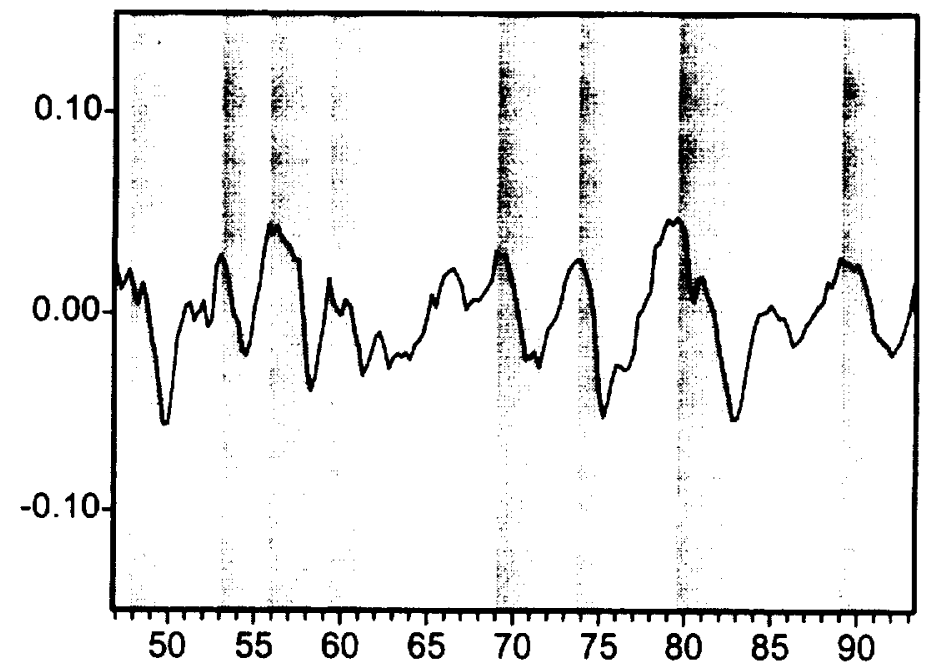

Figure 2 shows the medium-frequency component of hours. It shows the two major episodes that occurred over the postwar period. From 1947 through 1966, hours of work per member of the population fell below trend. From 1966 to 1990, hours grew above trend. The medium-frequency component turned down after 1990, but it is too early to see if this new development will persist. Again, periods of contraction of hours relative to trend are shaded, and the chronology expressed by the shaded areas is used in all subsequent medium-frequency plots. The vertical scale is also the same in all mediumfrequency plots. The scale is about three times coarser for medium than for high frequencies. 
Figure 2. Hours of Work at Medium

Frequencies

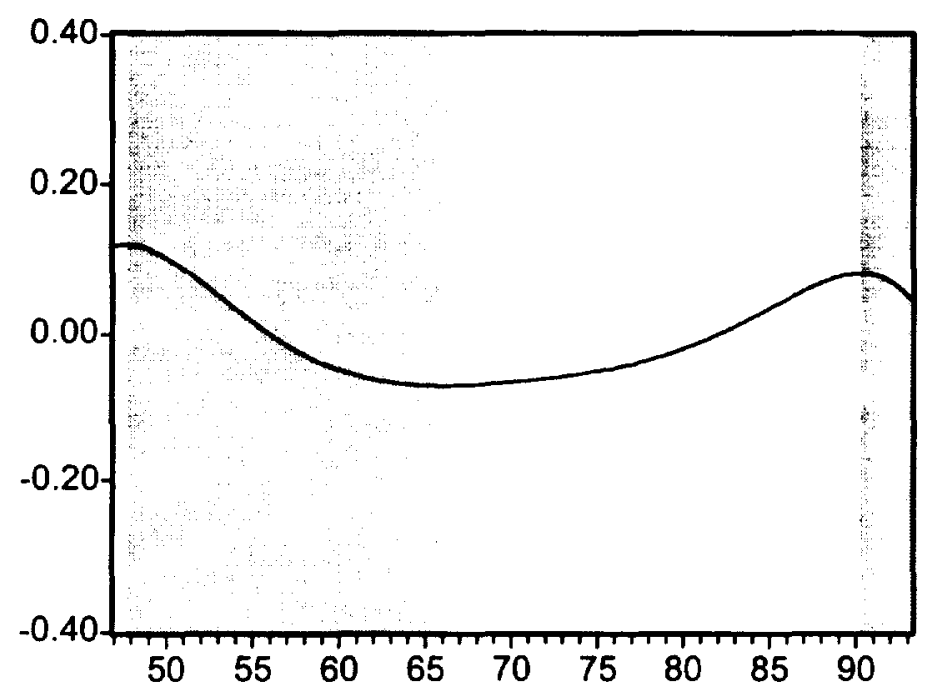

Figure 3 shows the high-frequency component of output per member of the population. Fluctuations in output track the chronology of fluctuations in hours closely. The familiar paradox of procyclical productivity shows plainly-movements in output are about as large as those in hours, when the elasticity of the production function with respect to labor input, measured by labor's income share, should be about 0.7 . Figure 4 shows the corresponding medium-frequency component of output. The component hardly changes over time. The productivity showdown started at almost exactly the same time as the speedup in hours per member of the population, and the two forces very closely offset each other.

Figures 5 and 6 show the high- and medium-frequency components of consumption per person. Consumption also tracks the hours chronology, but the magnitude of the fluctuations is below that of either hours or output. The consumption measure used here includes durables, but the high-frequency components of nondurables and services look remarkably similar. The decline in consumption in recessions is spread across all types of consumption and is not primarily in durables. As with output, there is relatively little movement of consumption at medium frequencies. 
Figure 3. Output at High Frequencies

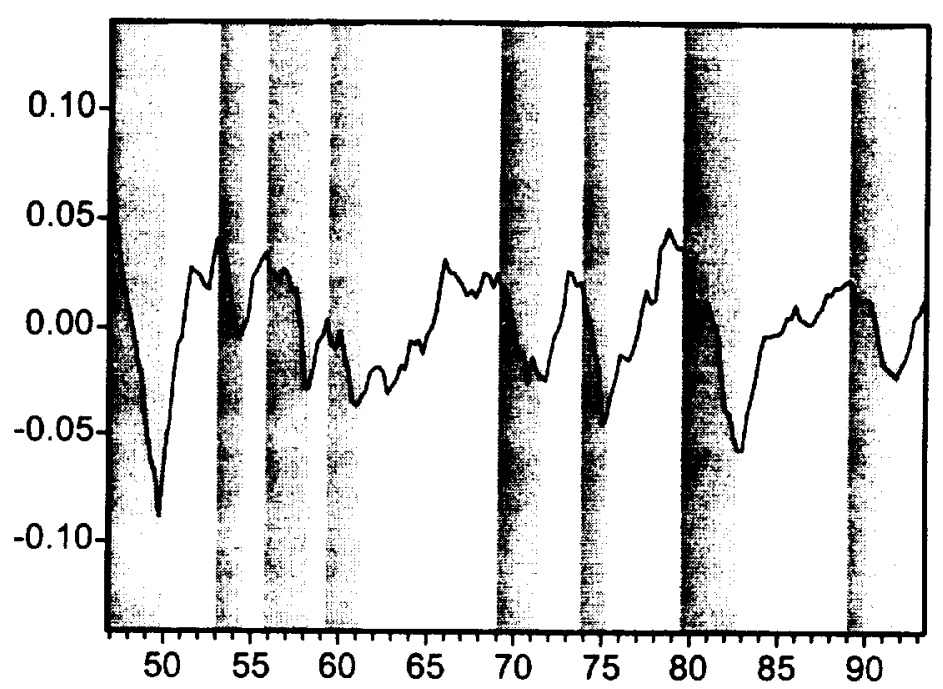

Figure 4. Output at Medium Frequencies

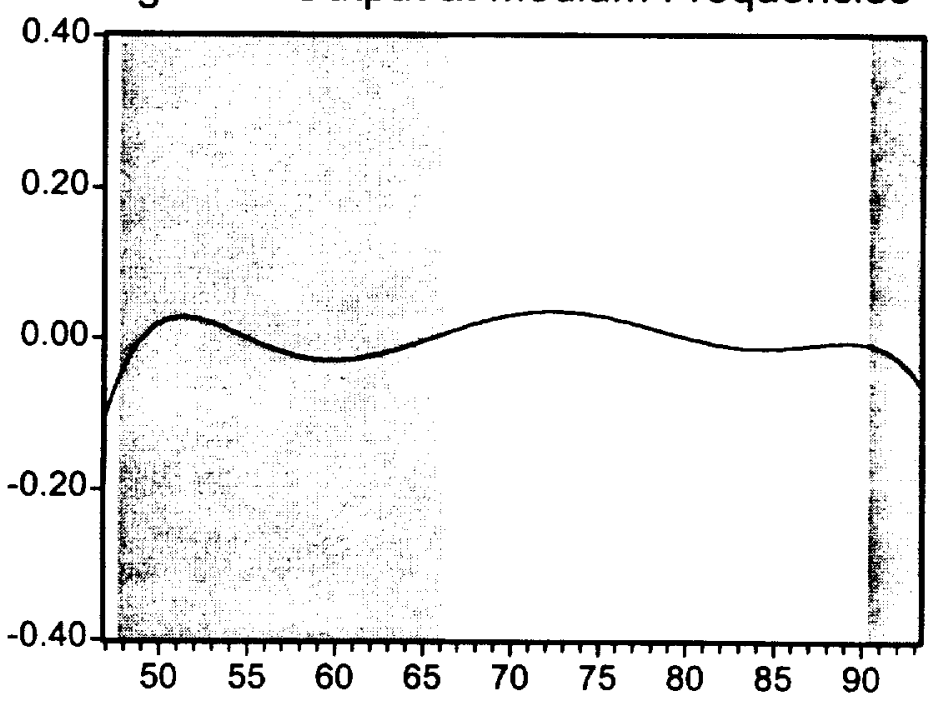


Figure 5. Consumption at High Frequencies

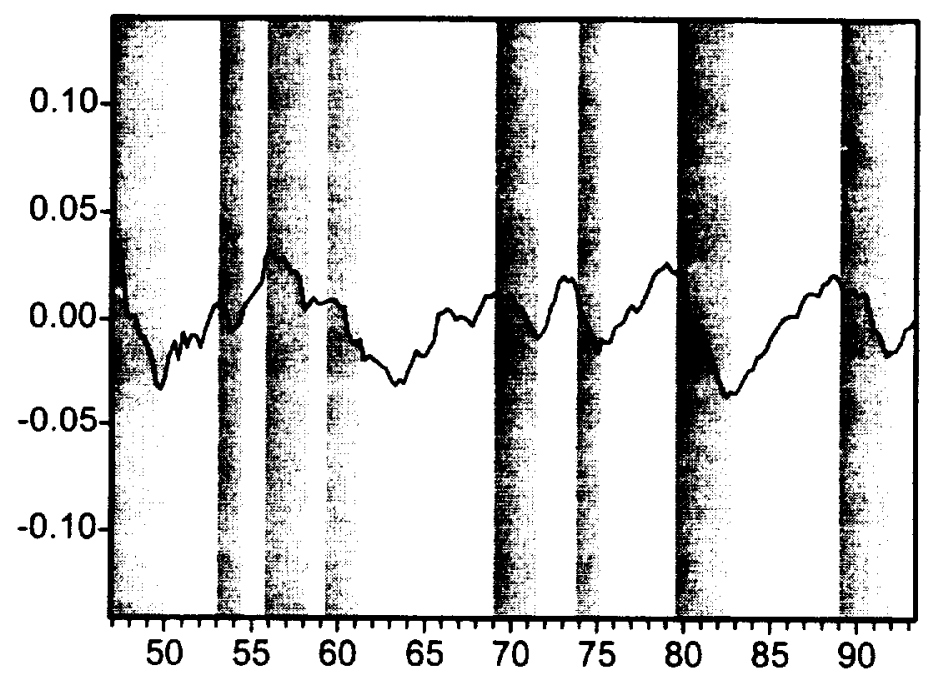

Figure 6. Consumption at Medium Frequencies

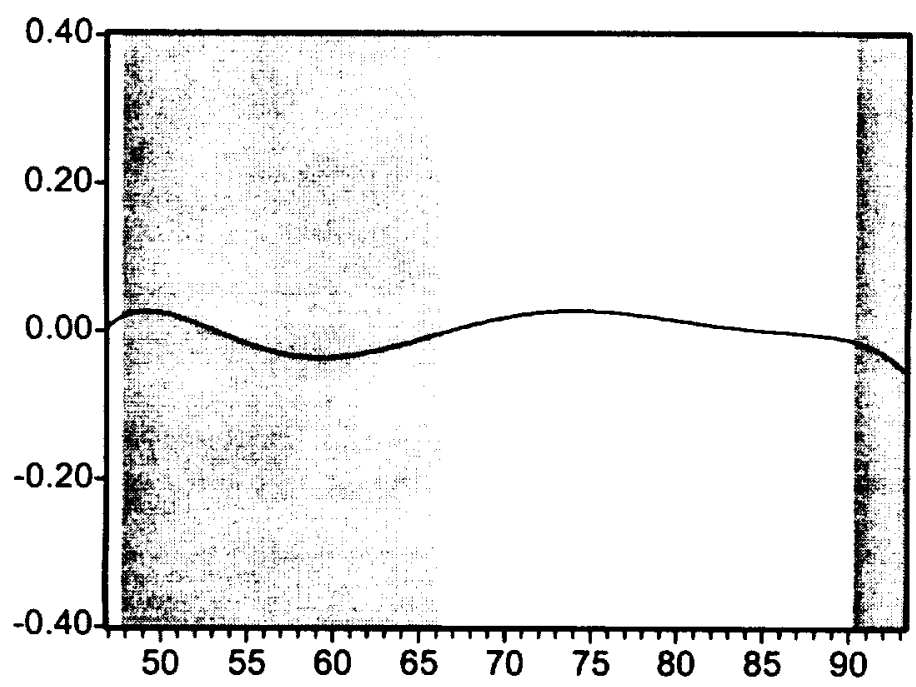




\section{Driving Forces}

Figure 7 shows the calculated values of the high-frequency component of $x$, the shift in the marginal rate of substitution between goods and time. When $x$ is high, households choose higher levels of goods consumption and higher levels of work. Shifts in the MRS are closely associated with each shaded contraction in employment. Recall that the formula for calculating the MRS shift is

$$
x=c-y+(1+\phi) n-\log \alpha
$$

Given the fact from Figures 1,3 and 5 that fluctuations in $n, c$ and $y$ are similar, it is inevitable that there will be large fluctuations in the MRS variable. ${ }^{6}$ In an economy without MRS shifts, the three variables can't move in the same direction by similar amounts. If technology improves, for example, consumption and output should rise by about the same amount, but hours should stay unchanged, in which case $x$ will not change. Or if government purchases rise, output and employment should rise, but consumption should fall, and, again, $x$ should not change.

Figure 8 shows that the same conclusion follows at medium frequencies. Figures 4 and 6 show that there is almost no medium-frequency movement in output and consumption. Thus the only possible explanation of the large movement in hours per member of the population at medium frequencies is the MRS shift. The cumulative movements at medium frequencies are much larger than any of the cyclical movement in the MRS.

\footnotetext{
${ }^{6}$ Parkin (1988) calculates the preference shift in the same way. I am still trying to resolve why he concludes that it is numerically tiny.
} 
Figure 7. MRS Shift at High Frequencies

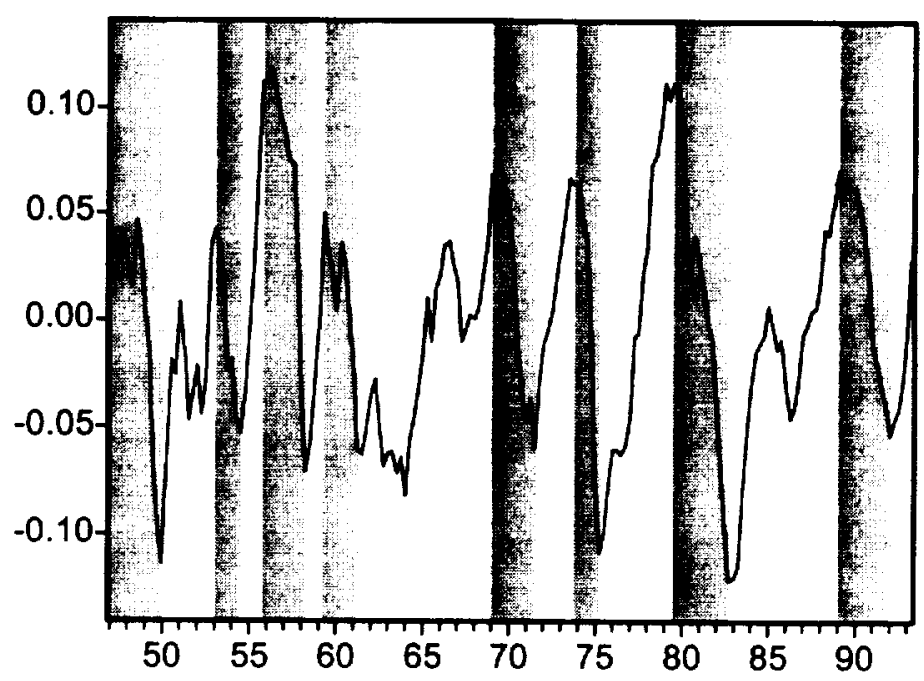

Figure 8. MRS Shift at Medium

Frequencies

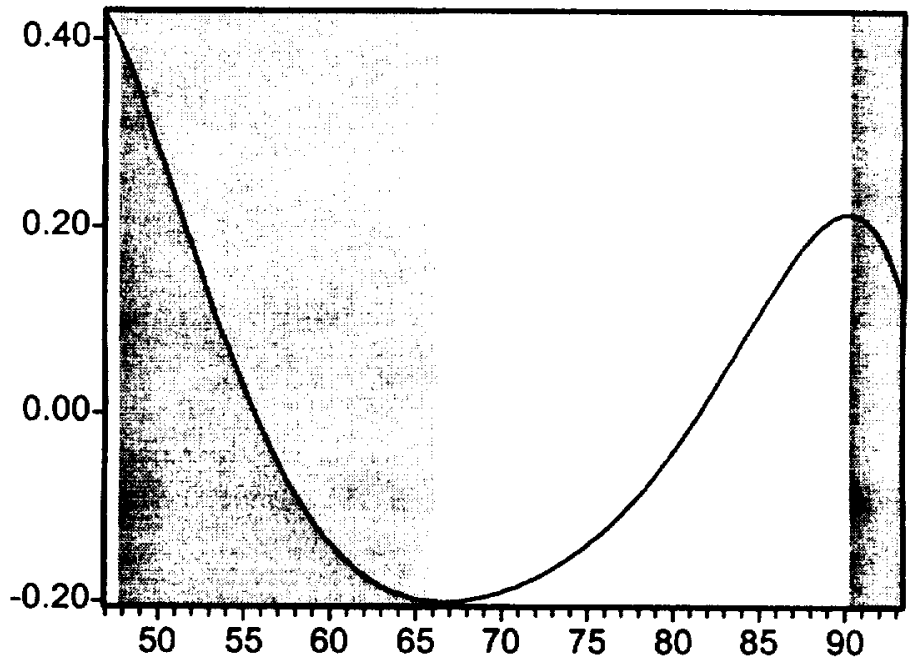

Figures 9 and 10 show standard results about cyclical and medium-frequency movements in productivity. The variable $z$ is essentially the cumulation of the Solow 
residual. There is considerable cyclical movement in the productivity measure. Figure 10 documents the productivity slowdown starting in 1972.

Figure 9. Technology Shift at High

\section{Frequencies}

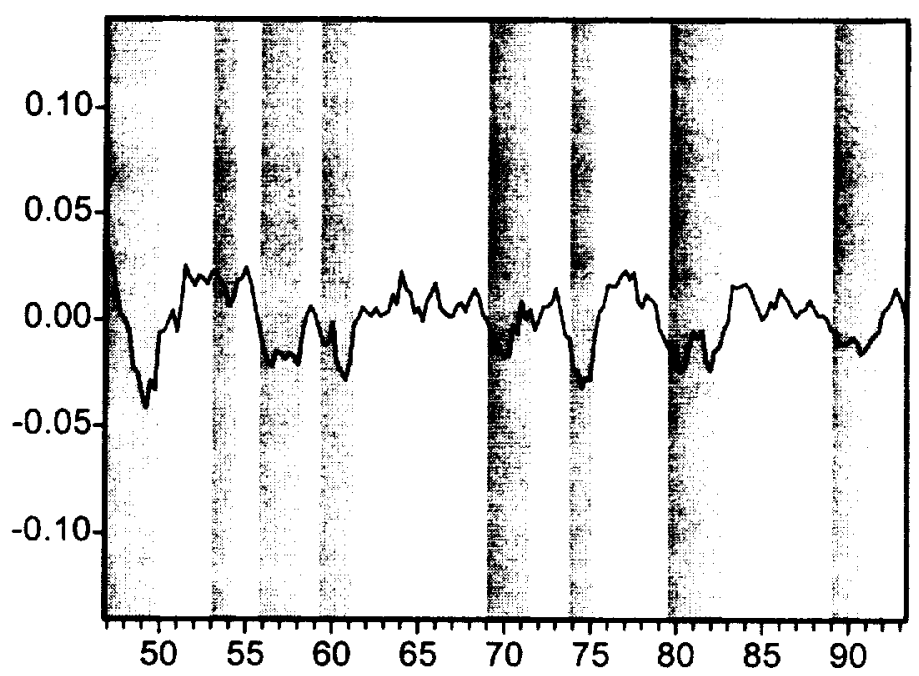

Figure 10. Technology Shift at Medium Frequencies

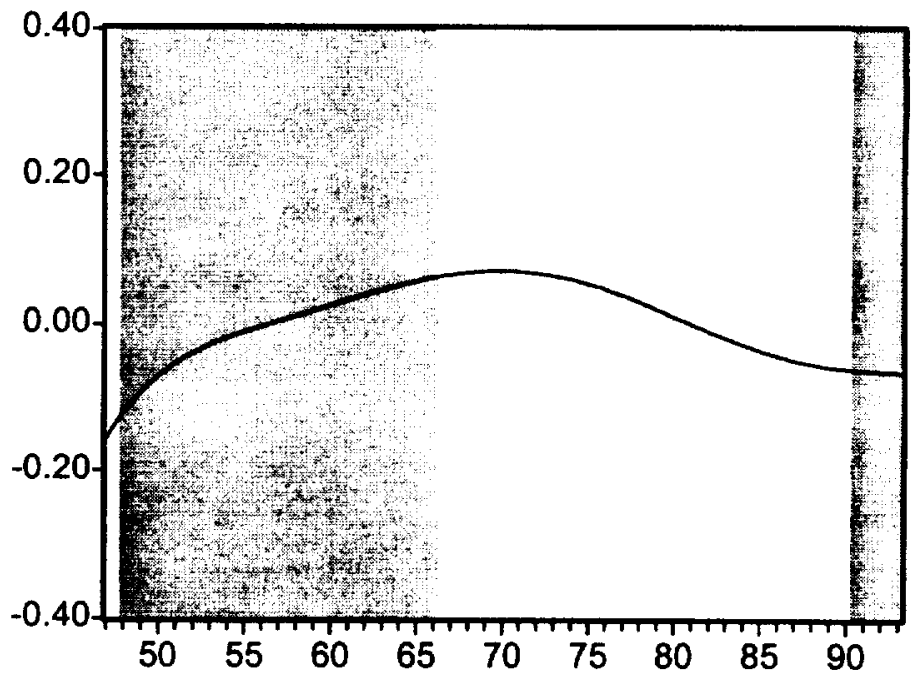


Figures 11 and 12 show government purchases. Purchases rose in most but not all recessions. But the amplitude of fluctuations in government purchases is much lower than that of the preference shift shown in Figure 7. The two driving forces can be compared directly because they have the same coefficient, $\lambda$, in the work effort equation. Figure 12 shows that there is little influence from government purchases at medium frequencies.

Figure 11. Government Purchases at High Frequencies

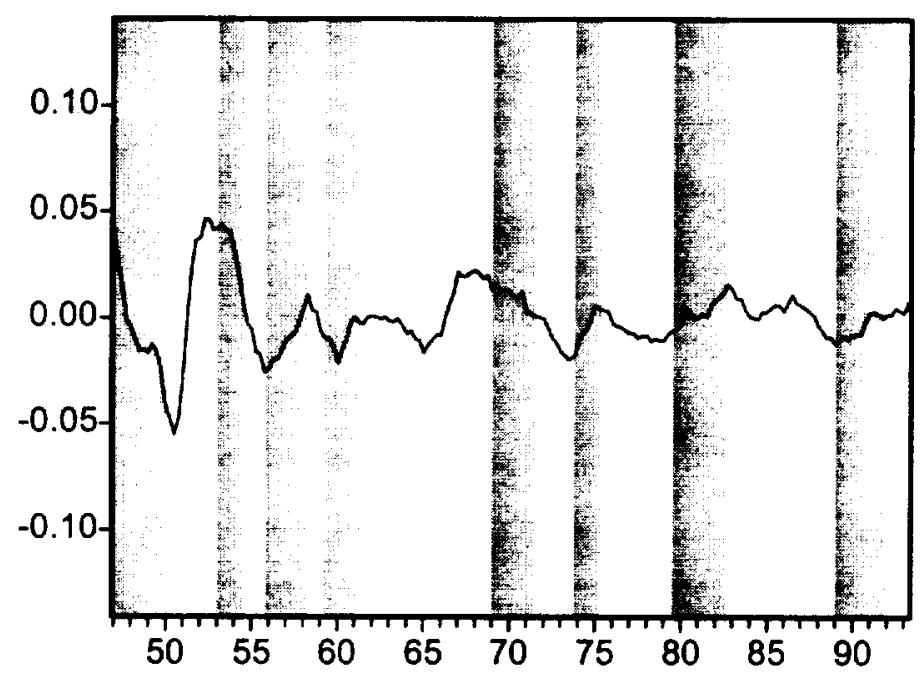

Figures 13 and 14 show investment, $v$. Recall that this variable combines investment and net exports. At high frequencies, investment tends to move in the same direction as work effort. Again, the amplitude of the fluctuations is much lower that the amplitude of the preference shifts in Figure 7. Figure 14 shows there are essentially no investment fluctuations at medium frequencies. 
Figure 12. Government Purchases at Medium Frequencies

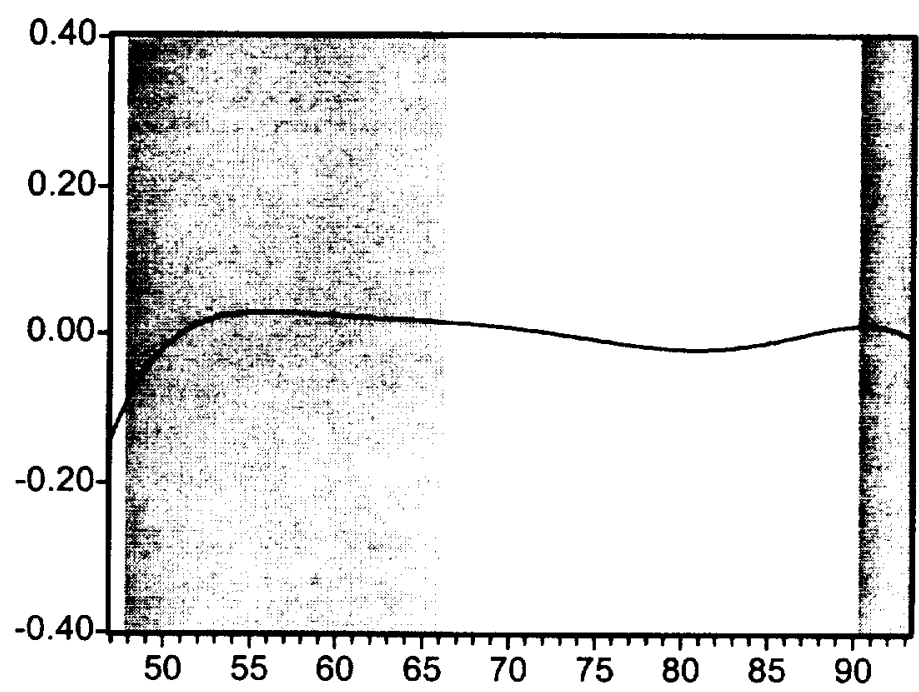

Figure 13. Investment at High Frequencies

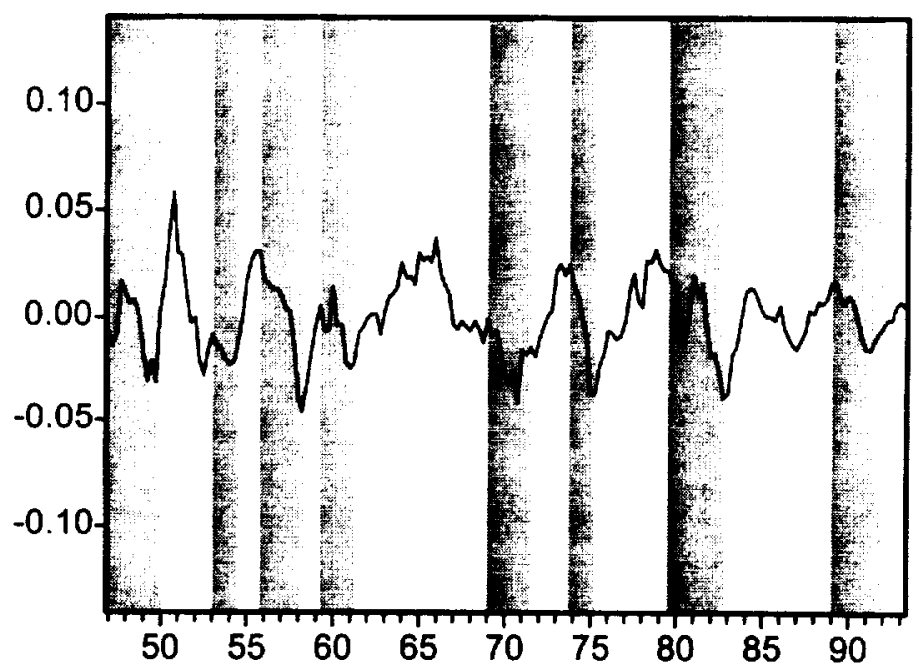


Figure 14. Investment at Medium

Frequencies

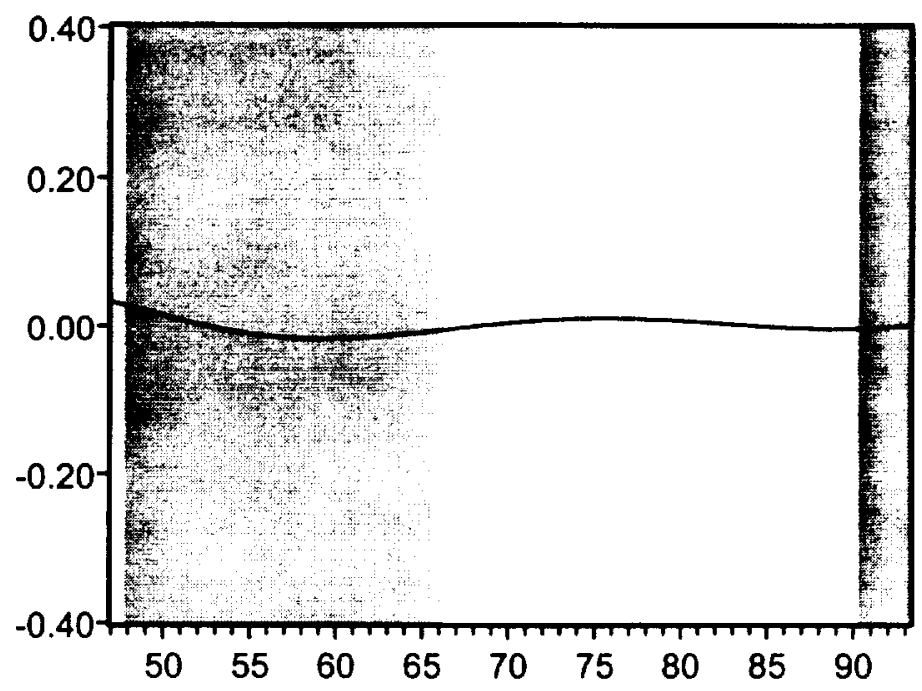

The results of estimating equation 3.1 are

$$
v=\underset{(.036)}{.242} x+1.050 z-.867 g+\frac{1}{(.131) \quad(116)} \varepsilon
$$

The coefficients shown are the sums of the four estimated coefficients for the current and three lagged values. $\varepsilon$ is the innovation in the residual component, $u$. There is a small intertemporal element associated with and amplifying the MRS shift, $x$. The technology shift, $z$, is positively associated with investment, as predicted by most intertemporal general equilibrium macro models. ' The intertemporal effect of an increase in government purchases, $g$, is in the expected negative direction, but this means that it largely attenuates the positive atemporal effect.

Figures 15 through 22 give the 6-way decomposition of movements in work effort based on equation 3.2. Figures 15 and 16 show the first two components, the atemporal and intertemporal parts of the effect of the preference shift on work effort. A comparison of these two figures to their counterparts for total hours, Figures 1 and 2, shows that at

\footnotetext{
${ }^{7}$ In particular, see Baxter and King (1991).
} 
both high and medium frequencies, the preference shift accounts for a large part of the movements of hours. A small part of the effect of the preference shift is intertemporal and a large part is atemporal.

Figure 15. Contribution of MRS Shift to High-Frequency Movements of Hours

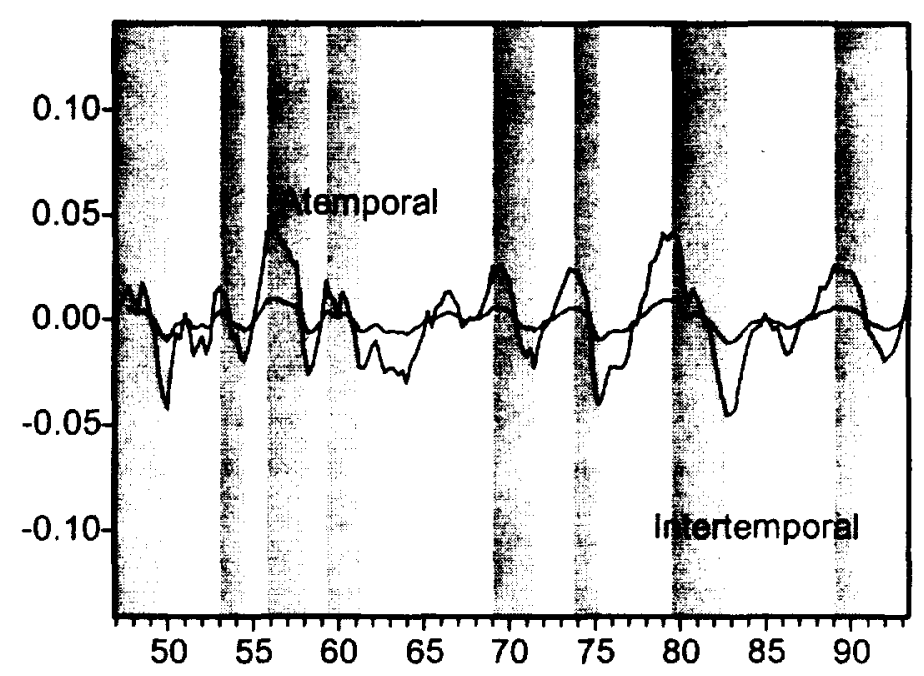

Figures 17 and 18 show that the contributions of the technology shift are small by all four measures. Technology shifts have no atemporal effect on hours of work; whatever influence they have on hours operates though intertemporal investment effects.

Figure 19 shows that the atemporal effect of government purchases is a small driving force at high frequencies, nowhere near as important as the preference shift effect shown in Figure 15. Figure 20 shows that there is no similar explanation of mediumfrequency movements in hours from either atemporal or intertemporal effects of changes in government purchases. 
Figure 16. Contribution of MRS Shift to Medium-Frequency Movements in Hours

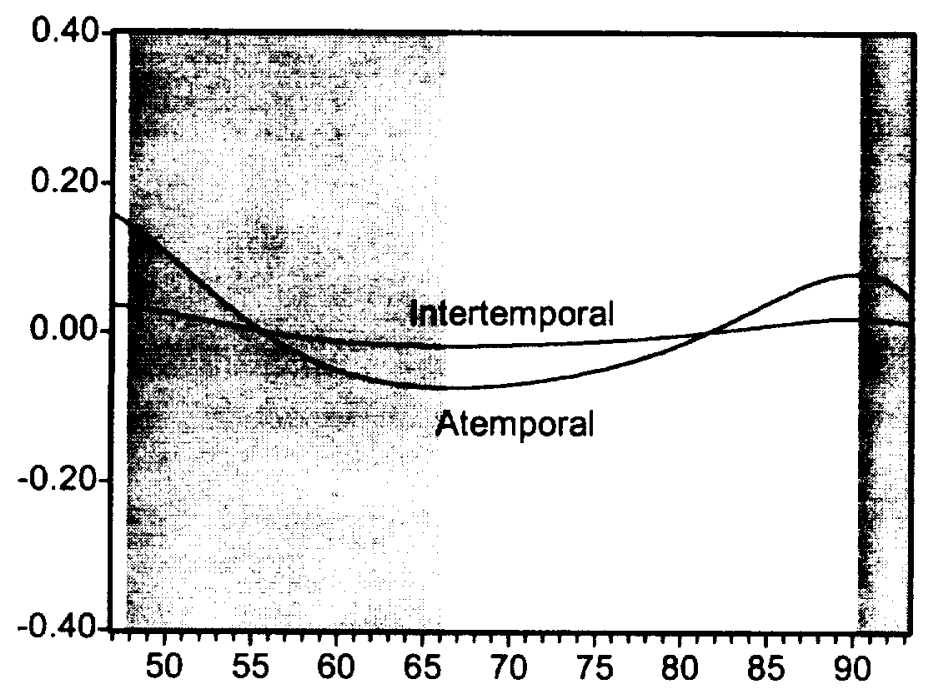

Figure 17. Intertemporal Contribution of Technology Shift to High-Frequency Movements in Hours

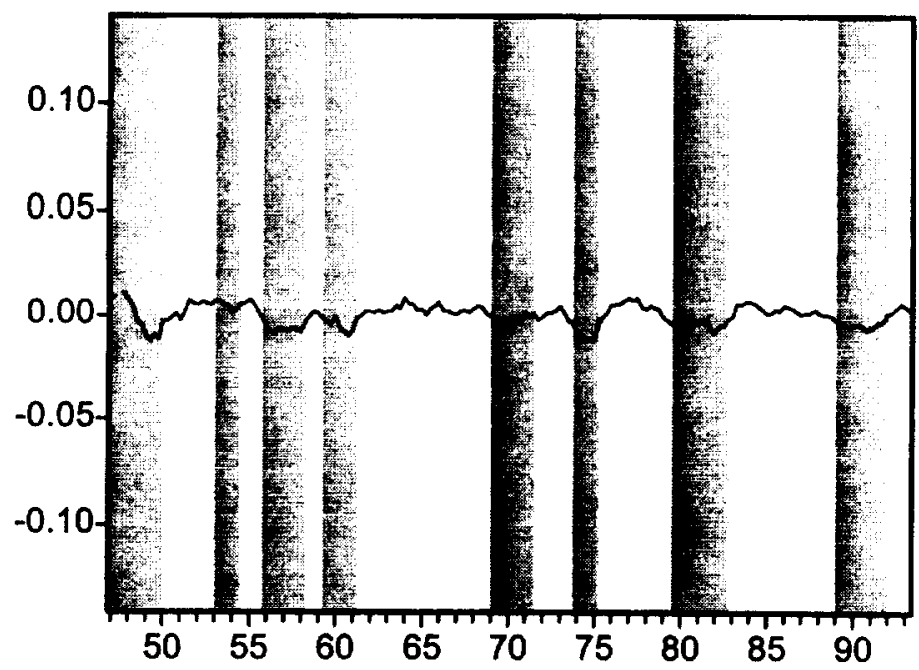


Figure 18. Intertemporal Contribution of Technology Shift to Medium-Frequency Movements in Hours

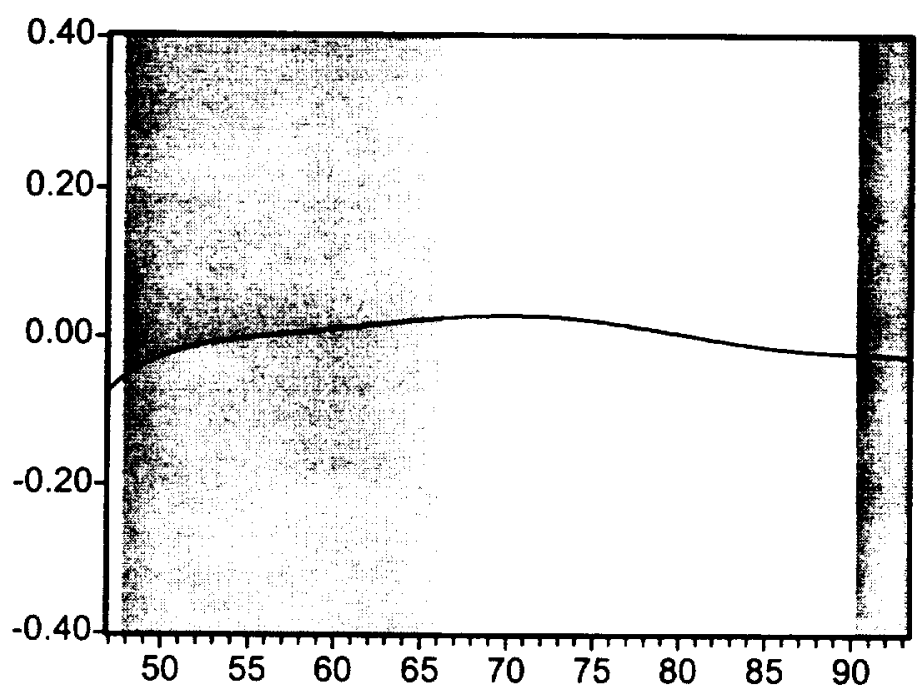

Figure 19. Contribution of Government Purchases to High-Frequency Movements in Hours

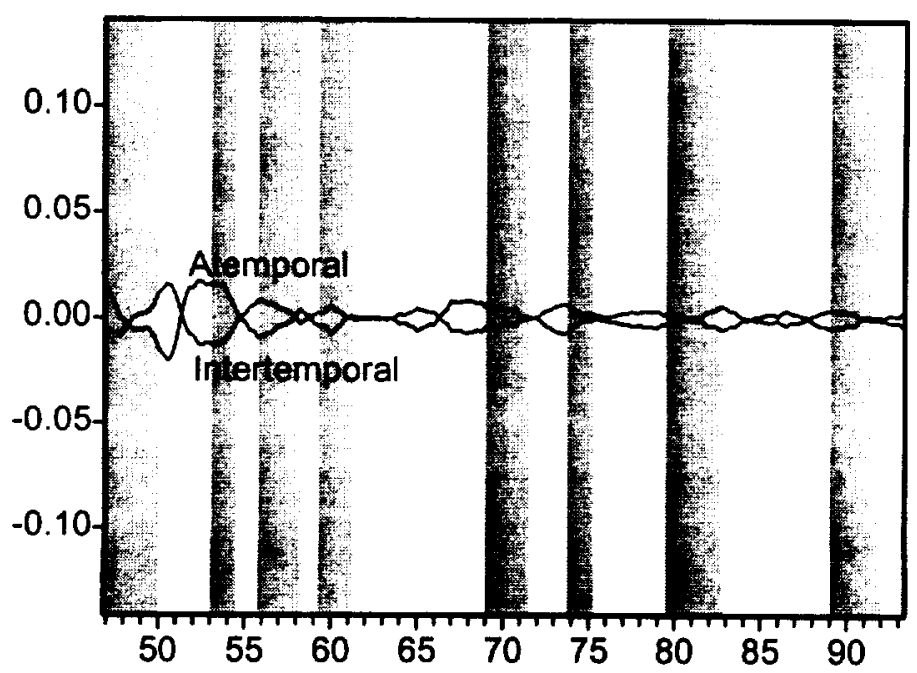


Figure 20. Contribution of Government

Purchases to Medium-Frequency

Movements in Hours

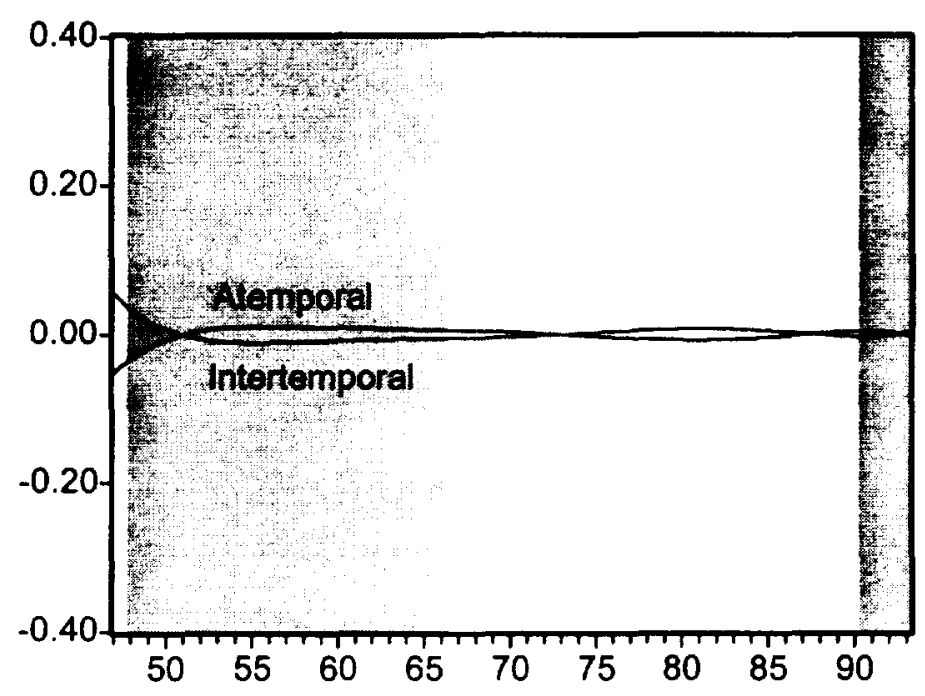

Finally, Figures 21 and 22 show the residual effects of all other influences on hours of work. Recall that the residual arises from movements of investment that are not induced by changes in preferences, technology, or government purchases. Although quite a bit of the movement of investment remains unexplained by equation 3.1, and the coefficient on investment in the atemporal relationship, equation 2.11, is quite large, the residual effects on hours are a small part of the story of the overall fluctuations in hours and no part of the explanation of the contraction of hours in recessions. The reason is shown in Figure 13-fluctuations in investment are not large in relation to the main driving force, the MRS shift. 
Figure 21. Contribution of Other Influences to High-Frequency Movements in Hours

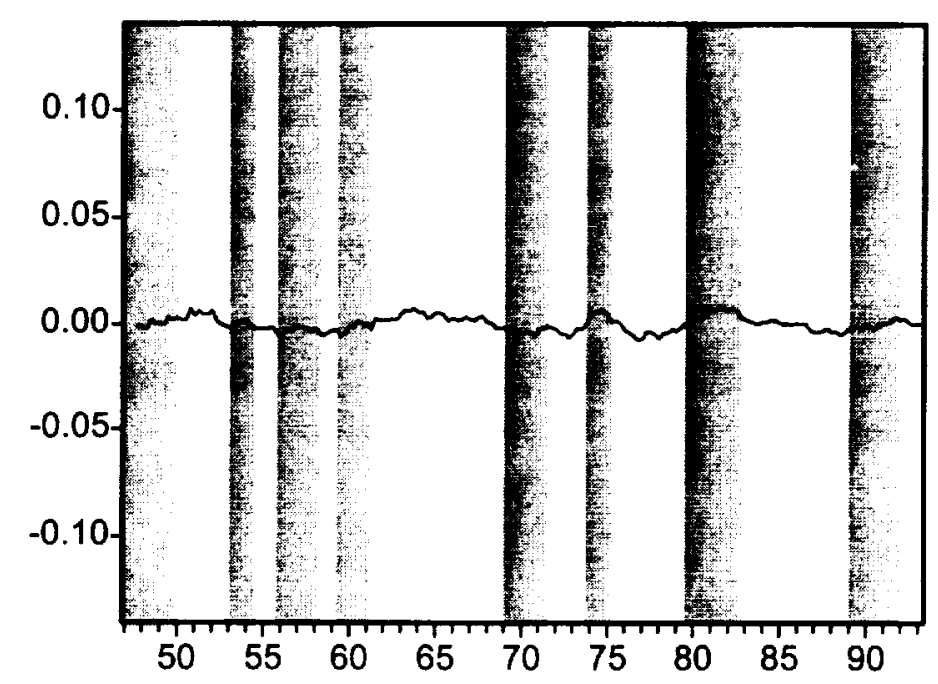

Figure 22. Contribution of Other Influences to Medium-Frequency Movements in Hours

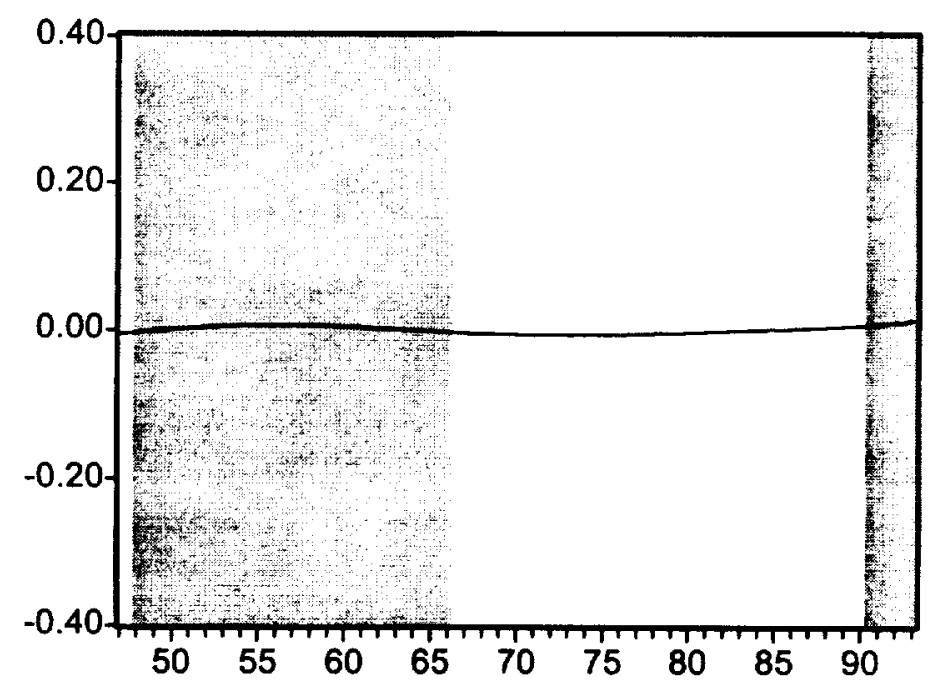

To summarize the findings about the relative importance of the various driving forces, I have calculated two measures of the importance of each term. The first is the 
covariance of the term with hours of work. I have normalized the covariances by dividing them by the variance of hours. The normalized covariances sum to 100 percent and can be interpreted as relative contributions to the variance. I have also calculated standard deviations of each term:

\begin{tabular}{|c|c|c|c|c|c|}
\hline \multirow[b]{2}{*}{ Component } & \multirow[b]{2}{*}{ Explanation } & \multicolumn{2}{|c|}{ High frequency } & \multicolumn{2}{|c|}{ Medium frequency } \\
\hline & & $\begin{array}{c}\text { Covariance } \\
\text { contribution } \\
\text { (percent of total } \\
\text { variance) }\end{array}$ & $\begin{array}{l}\text { Standard } \\
\text { deviation } \\
\text { (percent) }\end{array}$ & $\begin{array}{c}\text { Covariance } \\
\text { contribution } \\
\text { (percent of total } \\
\text { variance }\end{array}$ & $\begin{array}{l}\text { Standard } \\
\text { deviation } \\
\text { (percent) }\end{array}$ \\
\hline$n$ & hours of work & 100.0 & 2.25 & 100.0 & 6.16 \\
\hline$\lambda x$ & $\begin{array}{l}\text { atemporal effect } \\
\text { of preference } \\
\text { shift }\end{array}$ & 84.6 & 1.97 & 105.0 & 6.49 \\
\hline$\lambda \beta_{x}(L) x$ & $\begin{array}{l}\text { intertemporal } \\
\text { effect of } \\
\text { preference shift }\end{array}$ & 20.3 & 0.48 & 25.2 & 1.55 \\
\hline$\lambda \beta_{z}(L) z$ & $\begin{array}{l}\text { intertemporal } \\
\text { effect of } \\
\text { technology shift }\end{array}$ & -1.5 & 0.50 & -34.6 & 2.22 \\
\hline$\lambda g$ & $\begin{array}{l}\text { atemporal effect } \\
\text { of government } \\
\text { purchases }\end{array}$ & -1.7 & 0.58 & -7.3 & 1.00 \\
\hline$\lambda \beta_{g}(L) g$ & $\begin{array}{l}\text { intertemporal } \\
\text { effect of } \\
\text { government } \\
\text { purchases }\end{array}$ & 2.0 & 0.46 & 7.7 & 1.03 \\
\hline$\lambda u$ & $\begin{array}{l}\text { effect of residual } \\
\text { driving forces }\end{array}$ & -3.6 & 0.35 & 4.0 & 0.53 \\
\hline
\end{tabular}




\section{Related Research}

Kennan (1988) has studied employment fluctuations in a framework with some similarities to the one in this paper. He posits functional forms for preferences and technology and measures the relative importance of random shifts in both functions, although identifying the sources of fluctuations is a subsidiary goal of his work. But there are a number of crucial differences between his paper and this one. First, in order to deal with intertemporal issues in a model with a closed form solution, Kennan assumes that goods consumption enters preferences linearly. As he notes, this assumption means that wage variations have no income effect. Because the cancellation of income and substitution effects in the atemporal or long-run context is a core assumption of modern general equilibrium macroeconomic models, it is difficult to relate Kennan's findings to the issues considered in this paper. Kennan's assumption determines the real interest rate as a feature of preferences alone, and so imposes an unacceptably strong restriction on the intertemporal mechanisms prominent in modern macroeconomics.

Second, Kennan considers the joint behavior of employment and real wages only. He does not make use of data on output or consumption. Output could replace the real wage, as it does in this paper and many other papers in general equilibrium macroeconomics. Data on consumption are irrelevant given his strong assumption that consumption enters preferences linearly.

Third, Kennan treats the slope parameters of both preferences and technology as unknown. In order to identify the model, he makes the strong assumption that the two random shocks are predictable from their own past values only and not by any other variables. All his results turn on this assumption, which is hard to rationalize. By contrast, research in the Kydland-Prescott tradition has generally taken the view that technology (and later preference) shifts were measurable variables. For technology, the Solow residual-not dependent on unknown parameters-provides a natural measure. For preferences, there is no comparable non-parametric measure, but outside information can be used about the parameters of preferences. But even Kennan's strong assumption does not identify his model unambiguously. Instead, there are three isolated points in the parameter space that cannot be distinguished. In one of them, the preference shift is the dominant source of fluctuations in work effort. 
In another important paper closely related to this one, Eichenbaum, Hansen, and Singleton (1988) consider the hypothesis that non-time-separable preferences can explain the joint movements of real wages, consumption, and work effort, without invoking random shifts in preferences. They strongly reject a simple model with time separability and fixed preferences in favor of a model with non-time-separable fixed preferences. But, as they note,

We also found substantial evidence against the overidentifying restrictions implied by our model. There was, however, substantially less evidence against an alternative hypothesis that maintained only the intertemporal Euler equation relating aggregate consumption and hours worked to the interest rate. Under this alternative hypothesis, the statistical evidence against our original model is attributable to discrepancies between measured real wages and consumers' marginal rates of substitution between consumption and leisure. (p. 69)

In other words, a random shift in the marginal rate of substitution, as measured in this paper, would be one of the ways to explain their findings. Another would be the hypothesis that the measured real wage departs from either the marginal product of labor or the marginal rate of substitution, through the operation of wage-smoothing features of the employment relationship.

Benhabib, Rogerson, and Wright (1991) consider a driving force of the type suggested by the findings of this paper. In their model, recessions are times when household production is unusually efficient relative to production of market goods. Market hours of work and household purchases of market goods both decline because the household substitutes toward goods produced at home. Although Benhabib, Rogerson, and Wright consider a shift in technology rather than in preferences, that is a difference of terminology more than substance. One could write their household system as a reduced form with a random shift whose role would be the same as the preference shift considered here. Although Benhabib, Rogerson, and Wright observe that their household shift provides an account of the basic facts of recessions, they do not measure the importance of household shifts relative to other sources of fluctuations.

Cochrane (1994) concludes that the technology shock is a small part of the story of total fluctuations. He observes that, according to a Kydland-Prescott model, a bivariate 
vector autoregression of consumption and output should have only a single shock, namely the technology shock. In fact, the bivariate system has two shocks, and the one whose properties are unlike those of a technology shock accounts for most of the variation in the data. An extended version of the same analysis casts doubt on the importance of shifts in government purchases and in disturbances from monetary or credit sources. Finally, Cochrane considers movements of consumption that might arise from information available to households but not to the econometrician. He concludes that this type of information might be able to account for movements of consumption that otherwise appear to be spontaneous. Cochrane's investigation does not consider shifts in preferences as a potential driving force, nor does it consider the use of time in purposes other than working in the market and consuming leisure at home.

\section{Interpretation and Conclusions}

In a model based on standard neoclassical ingredients, the prime driving force in fluctuations turns out to be shifts in the marginal rate of substitution between goods and work. Recessions are times when people would rather consume smaller volumes of market goods and services and work correspondingly less. The case is strong that other candidates, namely shifts in technology and government purchases, have only a small role in fluctuations in hours of work. Though shifts in technology appear to be reasonably large, their effects on work effort almost certainly must operate through intertemporal mechanisms; certainly this is true of the numerical general equilibrium models where large effects of technology shifts have been found. But the small amplitude of movements of investment-the mediating variable of all intertemporal influences-rules out any significant role for shifts in technology. Shifts in government purchases are not nearly large enough to give much role to them in explaining recessions, even though the elasticity of hours with respect to government purchases is fairly large. And even the catchall residual influence has little role in explaining fluctuations in hours. Like the technology shift, the residual must operate through the intertemporal channel, and the behavior of investment rules out any important explanation through this channel.

The finding that the preference shift bears almost all of the burden of explaining recessions should be the starting point for research, not a final conclusion. A recession is 
indeed a time when people spend fewer hours in paid work and consume a lower volume of market goods and services. We need a much more intensive examination of the uses of time other than in paid work-such as time spent looking for work. The challenge to macroeconomics seems to be more in areas of atemporal analysis than in intertemporal analysis. 


\section{References}

Baxter, Marianne, and Robert G. King. 1991. "Productive Externalities and Business Cycles" Discussion paper 53, Institute for Empirical Macroeconomics, Federal Reserve Bank of Minneapolis. November.

Bencivenga, Valerie. 1992. "An Econometric Study of Hours and Output Variation with Preference Shocks" International Economic Review 33:449-471. May.

Benhabib, Jess, Richard Rogerson, and Randall Wright. 1991. "Homework in Macroeconomics: Household Production and Aggregate Fluctuations" Journal of Political Economy 99:1166-1187.

Blanchard, Olivier Jean, and Danny Quah. 1989. "The Dynamic Effects of Aggregate Demand and Supply Disturbances" American Economic Review 79:655-673. September.

Cochrane, John H. 1994. "Shocks" Forthcoming in the proceedings of the Fall 1993 Carnegie-Rochester conference. January.

Eichenbaum, Martin S., Lars Peter Hansen, and Kenneth J. Singleton. 1988. "A Time Series Analysis of Representative Agent Models of Consumption and Leisure Choice under Uncertainty" Quarterly Journal of Economics 103:51-78. February.

Hall, Robert E. 1986. "The Role of Consumption in Economic Fluctuations" in Robert J. Gordon (ed.) The American Business Cycle: Continuity and Change. Chicago: University of Chicago Press for the National Bureau of Economic Research. 237-266.

Kennan, John. 1988. "An Econometric Analysis of Fluctuations in Aggregate Labor Supply and Demand" Econometrica 56:317-334. March.

Kydland, Finn, and Edward C. Prescott. 1982. "Time to Build and Aggregate Fluctuations" Econometrica 5):1345-1370. November.

Parkin, Michael. 1988. "A Method for Determining whether Parameters in Aggregative Models Are Structural" Carnegie-Rochester Conference Series on Public Policy 29:215252. Autumn.

Shapiro, Matthew, and Mark Watson. 1988. "Sources of Business Cycle Fluctuations" NBER Macroeconomics Annual. 111-148. 